\title{
Case study on 3D printing education in fashion design coursework
}

\author{
Yu Mi Kwon ${ }^{1 *}\left(0\right.$, Young-A Lee ${ }^{2}$ and Sook Jin Kim
}

\author{
*Correspondence: \\ kwon.yumi@sejong.ac.kr \\ ${ }^{1}$ Department of Fashion \\ Design, Sejong University, \\ 209 Neungdong-ro, \\ Gwangjin-gu, Seoul 05006, \\ South Korea \\ Full list of author information \\ is available at the end of the \\ article
}

\begin{abstract}
In the past 10 years, the use of 3D printing (3DP) has been increased in a number of industries. However, its use in the fashion industry and education is still at the early stage. This study aimed to provide (1) a general overview of 3DP in fashion and its integration in fashion education and (2) a pedagogical guidance to educators in the fashion discipline by presenting one case of 3D printing education in fashion design courses. This case study focused on the importance of 3D printing in fashion design curricula and the way to strategically integrate this technology into the curriculum. Rhinoceros (Rhino) and FINEBOT were used for 3D object design and printing, respectively. The coursework consisted of theoretical lectures including definition and application of 3D printing; training of Rhino use; methods of producing objects; 3D modeling of creative objects; and 3D printing practice. During this coursework, the course instructor allowed for students to initiate their design and create the 3D objects on what they wanted. Challenges for educators were identified when fashion students were learning 3D modeling software; however, the coursework resulted in increased interest and understanding of the students in 3D modeling and printing of more advanced fashionrelated objects.
\end{abstract}

Keywords: 3D printing, 3D modeling, Fashion design education, Wearable products

\section{Introduction}

Nowadays 3D printing (3DP) is being actively introduced even to the fashion field as a new item. According to the data by Wohlers Associates, a specialist of 3DP market research, it is forecasted that the world 3DP market will grow to the scale of 21 billion US dollars in 2020 from 3.07 billion US dollars in 2014, with the annual increase of 31.3\% on average (Columbus 2015). According to Wohlers Associates, the market shares of the world 3DP industry as of 2013 were $77 \%$ of the US, followed by $11 \%$ of Germany, $2 \%$ of China, $2 \%$ of South Korea, and $8 \%$ of others including Japan, UK, Holland, and Russia. Accordingly, the Korean government, in 2014, set up the goal to establish 5 worldclass companies with its vision to be a leading country in the 3DP field by 2020 with the increase of the world market shares to 15\% (Lim 2014).

With the increasing interest in mass-customized and personalized products in today's society, 3DP has been paid in a great attention from diverse stakeholders in the marketplace and 3D printers have been using for creating mass-customized products such as medical parts, parts of electronics, architectural models, and sports equipment. Fashion

(c) The Author(s) 2017. This article is distributed under the terms of the Creative Commons Attribution 4.0 International License (http://creativecommons.org/licenses/by/4.0/), which permits unrestricted use, distribution, and reproduction in any medium, provided you give appropriate credit to the original author(s) and the source, provide a link to the Creative Commons license, and indicate if changes were made. 
industry also has started to use 3DP for developing prototypes, customized products, and artistic fashion items (Mau 2013). According to the research by an Australian research company, IBISWorld (2017), consumer products are considered for the highest sub-classified markets of 3DP (37.7\%), followed by aerospace and automotive (23.6\%), healthcare (19.2\%), architecture (8.8\%), and others (19.5\%). The consumer products taking the highest occupancy rate include the items that can provide consumers with trendy and unique design such as jewelry and shoes, which are broadly considered as fashion items. As shown in the markets, use of 3DP in the fashion industry has a great potential to attract trendy consumers in our current and future fast changing society.

Recently, academic researchers in the fashion discipline also have joined into this technology movement and started to publish work on 3DP and its application in fashion, including reviewing 3DP technology in fashion (Yap and Yeong 2014), types and characteristics of 3D printers (Shin 2015), diverse methods of object production with 3D printers including 3DP materials (Baek 2015; Melnikova et al. 2014), 3DP use and its current trends in the fashion industry (Kim and Kang 2015; Kim and Lee 2015; Park and Yoo 2016; Song and Geum 2016; Vanderploeg et al. 2016), and consumer perceptions of 3D printed apparel and 3D printers (Perry 2017). However, this research movement is still novel and academic research is lack on the pedagogical approach of 3DP education and practice in higher education, especially in fashion-related disciplines. Since the 3DP market is expanding over the world and its application is extending to diverse fields including the fashion industry, it is crucial to embed 3DP, as a new way of production called digital manufacturing, into the existing fashion design curricula and educate fashion design students as emerging professionals for the fashion industry.

A speech of the former US president Obama on 3DP, that it "has the potential to revolutionize the way we make almost everything" (Shapeways 2013), was a huge motivation for the academic society as well as the industry to realize the importance of 3DP and its manufacturing innovation (Gross 2013). His cabinet made a policy for digital machine tools including 3D printers with high expectation for the purpose of restoring the manufacturing industry in America, which has been declining gradually (Gross 2013). Thereafter, the US government reported a program plan to open a laboratory fully equipped with digital machines in 1000 schools for 4 years, in early 2012 (Hyun 2015). In August 2012, they reported a plan to establish the National Additive Manufacturing Innovation Institute (NAMII), a facility to research and develop 3DP technology, in Ohio and to invest 30 million US dollars in these activities (America Makes 2013; Hyun 2015). In short, the Obama government chose 3DP as a secret card to revive 'Made in America', and considered 3DP education as an important policy.

The Obama's statement on 3DP as "the potential to revolutionize" have influenced to the Korean government's strategic plan, in 2014, to provide 3DP education to 10 million people, about a quarter of total population of South Korea, in order to make 'Korea of using the 3D printer best' (Song and Seok 2015). To implement this plan, the Korean government has formed the conditions for the people to use 3D printers in their routine life by (1) offering 3DP education to 10 million people including elementary and secondary school students, adults, and startup founders by 2020 and (2) supplying 3D printers to the imagination labs as well as making maker spaces for self-production in schools. 
The introduction of this Obama's initiative on 3DP has led to increase people's interest in 3DP remarkably in all manufacturing industries including the fashion industry, in South Korea. 3DP permits to save time and cost in producing prototypes, well suits the production of small quantity rather than mass production, and allows the creation of diverse product types that fulfill different consumer needs and desires. Considering current consumer demands in the fashion industry (e.g., fast, unique, and personalized items), 3DP may be an optimal technology to fully integrate into the product design and development process in the fashion industry. Therefore, it is important for the higher education, especially fashion-related programs, to update the current curricula to respond the market changes so that their graduates can be compatible and ready for the technology-driven job markets in this industry.

The Korean government has encouraged the higher education not only to provide 3DP education for related majors (e.g., industrial engineering) but also to operate imagination labs where any students can make prototypes based on their own ideas. Some universities in South Korea offer 3DP training courses for instructors (i.e., Gunsan University, Keumoh National Institute of Technology), and others have extended 3DP education to all of their students as a general core course requirement beyond curricula of their majors (i.e., Pusan National University, Kyungbok University) (Song and Seok 2015).

In spite of this general movement of 3DP and addictive manufacturing innovation in the higher education in South Korea, 3DP education for students in fashion-related majors is still at the early stage. Although researchers in some other disciplines (e.g., mechanical engineering, art education) published the work on 3DP education (Lee et al. 2015; Lee 2015), no such an article was identified, considering 3DP as a pedagogical approach in fashion-related disciplines. Our paper emphasized the 3DP implementation in a fashion program, which may provide for instructors at other institutions to adapt this pedagogical approach for advancing their fashion curricula. For this study, we defined the term, fashion, as a popular trend, especially in styles of dress and ornament or manners of behaviors, which is not only limit to clothing items. This covers any type of products including accessories (e.g., rings, belts, hats, socks) and household items (e.g., bottle, cup, utensils).

In addition, engineering-based 3D modeling software have been taught at many private institutes; however, their curricula are mostly organized for general product design and (or) 3D modeling software learning instead of being specialized into 3D wearable fashion product design (e.g., dress, jacket). 3DP tutorials have been provided by most of 3D printer manufacturers, but this simple tutorial (e.g., making a simple 3D object) is in sufficient for fashion students to design sophisticated wearable products using 3DP. Therefore, the course used for this experimental case study was indeed a great trial (1) to introduce 3DP to fashion design students by integrating this topic into the fashion design curriculum and (2) to experiment 3DP education in fashion for one semester in order to seek out suggestions, which can guide for future implementation of 3DP.

Considering much of 3D printed products currently available on the market (e.g., shoes and accessories), 3DP education is urged to integrate into the current curriculum of fashion design majors so the graduates of those are much viable for their potential employers in the fashion industry. Therefore, this study aimed to provide (1) a general overview of 3DP in fashion and its integration in fashion education and (2) a pedagogical 
guidance to educators in the fashion discipline by presenting one case of introductorylevel 3DP course in the fashion design major. This case study focused on the implementation of 3DP in fashion design curricula and the way to strategically integrate this technology into the curriculum. Since this 3DP course was an experimental and first trial in the fashion design department at the institution, we framed this 3DP course to introduce the 3DP concepts to fashion students through designing and developing simple and small 3D objects so the students majoring in fashion design can gain basic concepts and reasonable skill sets to take advanced 3DP courses on wearable products that is planned to be offered in the future.

\section{Literature review}

\section{D printing technology and its related work}

With the advancement of 3DP technology, its applications have been extended to diverse disciplines (e.g., architecture, medicine, industrial design) and the use of 3DP has been gradually increasing in the fashion-related fields (Kuhn and Minuzzi 2015). Leading active wear brands such as Nike, Under Armour, and Adidas are the great examples for the use of 3DP in their product design and prototyping stage.

Nike has used 3DP to produce the prototypes of their products emphasizing on their personalized performance. For instances, they produced Nike Zoom Superfly Flyknit by using 3DP for the national athlete Allison Felix of the US, in technical tie with Hewlett-Packard. In general, when a shoe is produced for a certain athlete, the shoe is first made and then the athlete gives feedback after trying it on. Thereafter, the process that the revised one is produced and the athlete gives feedback is often repeated. It normally takes 3 months per process cycle for the actual shoe production or manufacturing stage, but the use of 3DP can reduce the period of time to only several hours for the shoe prototyping. Consequently, the athlete could have the best fit of shoes (Nike News 2014, 2016; Engadget 2016).

Under Armour also produced the sneaker 'Archi-Tech Futurist', having the stand out design feature of the 3D printed sole. This mid-sole has become to provide infinite cushioning and support the body weight more stably. It has not yet reached mass production, being produced in a small quantity as limited edition (McKenna 2016; Under Armour 3d-architech 2016; Garfield 2016). Adidas adopted the 3DP as well for shoe production, which is planning to apply it for custom-tailored production. For this product in the brand name of '3D Runner Pump', they applied the 3DP to their technical part as Under Armour does (Adidas Group 2015; Burgess 2016). Reebok utilized the 3DP to the exterior design of their shoes. The outer-sole of 'Liquid Speed' was produced through 3DP. The outer-sole produced in such way has more enhanced supporting and resisting power (Reebok News Stream 2016).

This 3DP technology has also been utilized in high-end designer collections of the fashion industry as conceptual or prototyping pieces rather than commercially marketable designs. Iris Van Herpen, a Dutch fashion designer, is well known for presenting experimental designs by applying the 3D technology to the couture fashion industry (Logan 2015; Luimstra 2014, 2015). For the first time, she presented her design works to which 3DP was applied in the $2011 \mathrm{~S} / \mathrm{S}$ Collection; and thereafter, she has shown her designs of using 3DP until the 2016 F/W Collection. Her works are noticed due to their 
formative and artistic expression by the use of 3DP; and especially in the $2013 \mathrm{~S} / \mathrm{S} \mathrm{Col-}$ lection held with the theme 'Voltage', she showed mysterious beauty by visually expressing the invisible power and kinesthesia from electric energy of human body. Taking the opportunity of this Voltage collection, she became to be recognized as the leading experimental designer using the 3DP technology (Iris Van Herpen n.d.).

In its $2015 \mathrm{~F} / \mathrm{W}$ Collection, Chanel also drew attention with ten suits of applying the 3DP. They used the objects of tweed jacket and skirt, which were made through 3DP as the material of clothes; or they connected the jacket sleeves or skirt hems in the mesh type of 3D printed materials (Matich 2015). Also, they attached beads or ornaments made by the use of 3DP to make an effect of looking like embroidery. In addition, much more business entities are introducing 3DP into their fashion items, including bow ties by Monocircus, a design studio of Japan (Designboom 2013); DNA 3D printed shoe by the designer, Pensar, based in Seattle, US (Pensar Development 2017); custom-tailored shoe ADAPTIV made by SOLS on the basis of 3D printing (3D printer and 3D printing news 2015); Fedora caps of MGX of Belgium (3D printer and 3D printing news 2013), which are made through 3DP process.

In spite of the fashion industry's increasing engagement of using 3DP in their design and 3D prototyping, academic research in this area is still limited on reviews of 3DP in fashion (Yap and Yeong 2014), 3DP use and its current trends in the fashion industry (Kim and Kang 2015; Kim and Lee 2015; Park and Yoo 2016; Song and Geum 2016; Vanderploeg et al. 2016), and consumer perceptions of 3D printed apparel and 3D printers (Perry 2017). Research on actual implementations of 3DP in fashion education has not been identified; therefore, our study could contribute to this undiscovered area of studies.

\section{D modeling software for 3D printing}

For 3DP, a form of addictive manufacturing for pre-production or production, it is necessary to first create 3D objects in a virtual space with 3D modeling software, which will produce a printable file to create a layer design. Diverse 3D modeling software is available in the market and the followings are common ones used for fashion-related product designs: MAYA, Rhinoceros (Rhino), AutoCAD, Sketchup, Zbrush, and 3Ds MAX. In order to create $3 \mathrm{D}$ wearable fashion products using 3DP, it is crucial for product designers and developers to be familiar with at least one of these 3D modeling programs. Characteristics of these widely using 3D modeling software are presented as follows.

The most widely using 3D modeling software is MAYA of Autodesk, Inc. (http://www. autodesk.com/products/maya/). It has technical functions of modeling, rendering and animation, and mainly adopts the polygonal method for 3D modeling. Any character or object form needed for 3DP can be created through 3D modeling tools. MAYA has functions of rendering to express brightness/darkness, shade and color on the basis of 3D modeling, as well as the model simulation. For this reason, MAYA is being used in diverse fields such as video program, animation, computer graphic, broadcasting, movie, online game production, and motion graphic.

Rhino is another popular 3D modeling software and considered as the more useful one for 3DP (http://www.Rhino3d.com/). Rhino uses the non-uniform rational B-splines (NURBS) method, which means 'a curve of informalized function', mathematically and 
accurately defining geometry of curve, surface, and solid. Rhino is the 3D modeling software with the most-advanced mathematical expression, enabling exact modeling of any form such as 3D surface and solid, as well as 2D line (Choi 2014; Nam 2012). Rhino has a remarkable file compatibility with almost all CAD data.

MAYA and 3Ds MAX use the subdivision modeling technology of a polygonal method; however, Rhino adopts NURBS method for 3D modeling, so it is mainly used in the applied areas which require precisions, such as jewelry or handicraft work as well as industrial design (e.g., automobiles, ships), architectural design, engineering, furniture and mold design. Rhino is difficult to learn at the beginning due to many functions of its tool; however, it gets easier to handle than other 3D modeling programs once a user becomes familiar with it, and it enables design modeling of whatever a user desires.

Sketchup of Trimble Navigation Limited is another 3D modeling software, which is commonly used due to the easiness to learn how to use and the cost effectiveness of the software (http://www.sketchup.com/). Sketchup is characterized by its warehouse-3D warehouse and extension warehouse. The former is a sharing platform enabling a user to upload for others to download and the latter is a plug-in sharing platform. Due to its advantage of having simple functions and being able to learn even for novices, it is extensively used for beginners in 3D modeling for 3DP as well as in architecture, landscaping, interior design, product design, and online games.

AutoCAD of Autodesk, Inc. (http://www.autodesk.com/) is the most powerful program out of 2D-based software, which is widely used as a leader of CAD fields, taking the highest market share in the CAD software market. AutoCAD is compatible with 3Ds Max of the same maker, so it is enabled in 3Ds Max to convert what is drawn in AutoCAD to the 3D model. However, it has several inconvenient aspects compared with other 3D modeling software, so it is not recommendable to use this software for 3D modeling for 3DP. Despite such disadvantages, AutoCAD is used in many fields including architecture, electricity, mechanic engineering and civil engineering.

Zbrush is 3D digital sculpting graphic software developed by Pixologic, Inc. (http:// pixologic.com/). Adopting the same polygonal method as MAYA, Zbrush has an advantage of making models of fine quality in a simpler way than other programs. A user can make easily and intuitively any mechanic forms as well as complicated objects. Zbrush is used not only in diverse fields that require fine modeling work (e.g., movies, animation, online games) but also in fine art and design, which is well compatible with MAX.

3Ds MAX of Autodesk, Inc. is a tool used mainly in online game and graphic design. MAYA is also popular for such fields, but many Korean online gaming companies prefer to use 3Ds MAX. It is also applied to architecture because of providing outstanding functions of modeling and animation, with excellence in illumination, simulation, and high-level shader of expressing the surface of objects. Table 1 provides the summary of popular 3D modeling software along with its characteristics and main applications.

\section{D printer types and materials}

With extensive applications and popularization of 3DP, many types of 3D printer are available using various manufacturing methods and materials (e.g., filament, power). Out of the additive manufacturing methods, the most commonly used one is the fused deposition modeling (FDM) that plastic material melted with heat is released through 
Table 1 3D modeling software available for 3D printing

\begin{tabular}{|c|c|c|c|}
\hline Software & Provider (website) & Characteristics & Main applications \\
\hline MAYA & $\begin{array}{l}\text { Autodesk (http://www. } \\
\text { autodesk.com/prod- } \\
\text { ucts/maya/) }\end{array}$ & $\begin{array}{l}\text { Modeling of the polygo- } \\
\text { nal method } \\
\text { Functions of modeling, } \\
\text { rendering and simula- } \\
\text { tion } \\
\text { Excellent function of } \\
\text { animation }\end{array}$ & $\begin{array}{l}\text { Video program, animation, } \\
\text { CG, broadcasting, movies, } \\
\text { online games, motion } \\
\text { graphics }\end{array}$ \\
\hline Rhino & $\begin{array}{l}\text { Rovert McNeel \& Associ- } \\
\text { ates (http://www. } \\
\text { Rhino3d.com) }\end{array}$ & $\begin{array}{l}\text { NURBS method } \\
\text { 3D modeling of most } \\
\text { advanced mathematical } \\
\text { expression method } \\
\text { Suitable for precise and } \\
\text { accurate design work }\end{array}$ & $\begin{array}{l}\text { Industrial design, architec- } \\
\text { tural design, engineering, } \\
\text { mold design, jewelry } \\
\text { design, handicraft design }\end{array}$ \\
\hline Sketchup & $\begin{array}{l}\text { Trimble Navigation } \\
\text { (http://www.sketchup. } \\
\text { com/) }\end{array}$ & $\begin{array}{l}\text { Sharing platform, provid- } \\
\text { ing warehouses, and } \\
\text { enabling a user to } \\
\text { upload } \\
\text { Simple and easy for 3D } \\
\text { modeling }\end{array}$ & $\begin{array}{l}\text { Architecture, landscape, } \\
\text { interior design, product } \\
\text { design, online games }\end{array}$ \\
\hline AutoCAD & $\begin{array}{l}\text { Autodesk (http://www. } \\
\text { autodesk.com/) }\end{array}$ & $\begin{array}{l}\text { Top leader in 2D-based } \\
\text { software } \\
\text { Several inconvenient } \\
\text { aspects in 3D modeling }\end{array}$ & $\begin{array}{l}\text { Architecture, electricity, } \\
\text { mechanical engineering, } \\
\text { civil engineering }\end{array}$ \\
\hline Zbrush & $\begin{array}{l}\text { Pixologic (http://pixologic. } \\
\text { com/) }\end{array}$ & $\begin{array}{l}\text { Modeling of the polygo- } \\
\text { nal method } \\
\text { Having a tool of sculpting } \\
\text { brush }\end{array}$ & $\begin{array}{l}\text { Movies, animation, online } \\
\text { games, fine art works, } \\
\text { design }\end{array}$ \\
\hline 3Ds MAX & $\begin{array}{l}\text { Autodesk (http:// } \\
\text { www.autodesk.com/ } \\
\text { products/3ds-max/ } \\
\text { overview) }\end{array}$ & $\begin{array}{l}\text { Biggest number of users } \\
\text { in the world } \\
\text { Compatible with several } \\
\text { plug-ins }\end{array}$ & $\begin{array}{l}\text { Architecture, online games, } \\
\text { graphics }\end{array}$ \\
\hline $\begin{array}{l}\text { Others (e.g., 123D Design, } \\
\text { Blender, NaroCAD) }\end{array}$ & $\begin{array}{l}\text { Autodesk, Blender Foun- } \\
\text { dation }\end{array}$ & $\begin{array}{l}\text { Simple function and intui- } \\
\text { tive UI } \\
\text { Easy making of simple } \\
\text { objects }\end{array}$ & Design \\
\hline
\end{tabular}

nozzle, in the form of layers which are added on the platform one after another (Noh and Lee 2016).

The plastic filament, the 3DP material, is made mainly of poly lactic acid (PLA) or acryl on it rile butadiene styrene (ABS) series material, normally in the wire form of 1.75 or $2.85 \mathrm{~mm}$ in diameter. PLA is a non-toxic eco-friendly material of which main ingredients are corn and sugar cane, which is contained in almost all 3D printers. It has an advantage of no transformation since it is not shrunk easily even with falling temperature. $\mathrm{ABS}$ has the advantage of low price, as thermoplastic plastic that is commonly used, but the disadvantages of harmful odor, or bending or cracks by rapid cooling due to high shrinkage. Many other materials are used in 3DP, including engineering plastic which is a suitable material for mechanic parts due to its excellent strength, heat resistance, and impact resistance; nylon filament which is more flexible and softer than PLA but has high shrinkage; and wood filament made by mixing the recycled wood with binding polymer. As of today, filament is of over 20 colors including white, silver, brown, black, red, and yellow (Noh and Lee 2016; Baek 2015).

Multi-jet-modeling (MJM) is another method that acrylic photopolymer, the material of printing model, is jetted from the print head like a inkjet printer, and then its 
layers are added one by one. It enables high precision and excellent curve processing, and has an advantage of controlling the transparency since the material is acrylic resin (Noh and Lee 2016; Hara 2015). Stereo lithography apparatus (SLA) is the method that a model is made by shooting UV laser into the water tank containing photopolymer resin of epoxy series (polymer liquid material changing into solid when laser is shot), and then hardening each layer. A printer has a water tank containing photopolymer resin. Since this method enables to form a model by the use of laser, so the quality of printed object is excellent and the printing speed is fast. However, it has shortcomings of difficulty to manage the printer due to the use of liquid material makes, and of expensive photopolymer resin (Noh and Lee 2016; Hyun 2015).

Photopolymer jetting (Polyjet) is the method of inkjet technology combined with photopolymer resin technology that liquid-type photopolymer resin jetted through the nozzle is added layer by layer on the forming plate, and hardened by UV laser. A precise model can be made by very thin layers added (Noh and Lee 2016; Hyun 2015). Digital light processing (DLP) is the method of printing that photopolymer resin is evenly applied to the bed floor, and the image is shot by projection beam and then hardened, and another layer is added. This method is used in a variety of fields of modeling, architecture, figure, jewelry, and dental care (Noh and Lee 2016). In addition, various types of 3D printing methods are utilized in diverse fields (e.g., direct metal printing, laminated object manufacturing, plastic sheet lamination) (Noh and Lee 2016; Shin 2015).

\section{Methods}

This experimental study aimed to provide a pedagogical guidance to educators in the fashion discipline by presenting one case of 3DP education that was implemented in one of fashion design courses during one semester, which focused on designing a simple and small 3D printed fashion accessories.

\section{Subjects of the case and 3D printing education}

The case used for this experimental study, with the 17 junior students majoring in fashion design, was from one of major institutions located in Seoul, South Korea. The institution has already been operating an imagination lab equipping with three 3D printers, since appointed as a software-centered university in 2015 by the Ministry of Science, ICT \& Future Planning of Korea, and Institute for Information \& Communications Technology Promotion. All 3D printers installed at the institution are the products in the brand of 'FINEBOT' produced by TPC Mechatronics (http://www.tpc3d.com/product_touchs.php). It adopts the FDM method, which is optimal to be used for higher education with lamination of $0.01-0.05 \mathrm{~mm}$, small and fine printing, and fast printing speed.

The Department of Fashion Design is housed within the university; teaching 2D fashion graphics to freshmen as a core subject and offering virtual fashion design to sophomores and juniors. Thus, the 17 students participated in this study were confident to use Adobe Creative Suites (e.g., Photoshop, Illustrator) in 2D graphics and were familiar with the way to use 3D virtual clothing design and prototyping software such as Marvelous Designer (https://www.marvelousdesigner.com/) and CLO 3D (https://www. clo3d.com/). The experiences of using various fashion-related software, especially the pre-stage of 3D modeling experience in a 3D virtual space, have allowed students to be 
more comfortable to introduce into 3D prototyping with 3DP and led to motivate them to learn 3DP process.

The instructor who taught this 3DP course obtained the doctoral degree in fashion design, was familiar with fashion-related 2D and 3D computer software, and have taught numerous technology-related courses in fashion (e.g., 3D virtual clothing design). To offer this experimental course on 3DP, the instructor self-learned the 3D modeling program, Rhino, its associated programs as well as the way to operate 3D printers.

Although the department has heavily incorporated cutting-edge computer technologies into the fashion design curriculum, 3DP was not the subject matter fully incorporated into the fashion design course until summer of 2016. Most institutions in South Korea have not been offering 3DP classes yet for students in fashion design majors as a core or supportive course. This relates with the high cost associated with equipping 3D printer and 3D modeling software and the difficulty to identify instructors who have credentials to teach 3DP geared toward specific fashion-related products. Therefore, this case study of 3DP education would be a useful guidance for fashion-related programs at other institutions if planning to offer 3DP related classes for the future.

\section{Use of Rhino as 3D modeling software}

Rhino was chosen for the 3DP coursework among many other 3D modeling software available for the following reasons: (1) using the most advanced equation of NURBS mathematics, which has an advantage of being able to make accurate 3D models, (2) being a small-sized but powerful modeling tool since it has been developed as the one specialized in 3D modeling, (3) being compatible with almost all existing CAD data due to various file forms of import or export, and (4) having flexibility and compatibility of file error checkup, STL file conversion and saving for 3DP after modeling is completed (Choi 2014).

\section{Slicing software CURA}

It is sometimes challenging for a 3D printer to directly read a file made from 3D modeling software. Therefore, it needs to convert STL data made from 3D modeling software into the path data sliced into layers, where each layer is as thick as one-time movement of printer head. This path data is called G-Code and the software converting into G-Code is called 'slicing program'.

Numerous slicer software is available in the software market (e.g., CURA, KISSlicer, Slic3r, Make Ware). CURA, having simple interface and being accessible for free version via their official website, was chosen for the 3DP coursework for this study, because of its easy use for novices to do 3DP (https://ultimaker.com/en/products/cura-software). There may be a problem in creating G-Code of an object in complicated structures, but CURA was suitable for the coursework with an objective of 3DP for simple fashion products (e.g., ring, pendant, button).

\section{Case scenario: 3D printing education}

The 3DP course entitled "Digital Fashion Design" was a junior level 3-credit course having $4 \mathrm{~h}$ of instructor contacts per week, for 16 weeks in fall semester of 2016 . However, during the lab session of printing with $3 \mathrm{D}$ printer, the students were also allowed to use 
$3 \mathrm{D}$ printer at the lab in out-of-class hours. The specific course objectives were for students to (1) understand the whole 3DP production process in fashion; (2) understand 3DP operating principles; (3) explore the areas 3DP can be applied; and (4) integrate obtained knowledge and skills into 3DP fashion-related item development. The course contents included the definition and basic process of 3DP, current trends of 3DP and its use in the fashion industry, 3D product design by the use of Rhino, 3D modeling software, and printing of 3D design objects with $3 \mathrm{D}$ printer.

More specifically, the class in the 1st week was for the overview of the course (i.e., 3DP introduction, methods of, 3D modeling software used for the course). In the 2nd5 th weeks, the students learned about the tools of 3D modeling software, Rhino. This is the program unfamiliar to the students and has so many functions, so enough time was plotted for the students to learn how to produce 3D objects by using its various tools. The students started to produce various objects by using Rhino during the 6th-10th weeks. During this time period, modeling of various types of ring, button, pendant, cup, vase and clock were practiced.

In the 11th week, 3D rendering practice was started. In 3D modeling, rendering is an important process to simulate the real image. During the 12th and 13th weeks, creative design planning and modeling were performed and the students made 3DP objects by converting into G-Code during the 14th and 15th weeks. During the last week of the 3DP course, they presented their 3DP works as their final project. During this last class time, a piece of papers were also distributed to the students and they were asked to provide comments on their 3DP learning experiences in general, challenges (e.g., use of appropriate Rhino tools when designing 3D products, 3D modeling process, 3D printing process), and suggestions for the advancement of this 3DP course.

The students' learning outcomes were tied with the specific course objectives mentioned above. They were evaluated on the basis of examining the followings: (1) class attendance, (2) weekly journals (e.g., the production process of 3D modeling), (3) 3D modeling files of fashion items to examine the accuracy of designs, (4) 3D printed outputs of their final project, and (5) completion of in-class activities (e.g., practicing Rhino tools, error correction of 3D objects, exercises of use of 3D printer).

To collect the data for this case study, the instructor of this course documented all of in-class activities, assignments, final project, in-class communications of the students with the instructor, and their comments submitted at the end of semester. The data from this 3DP course were analyzed using a qualitative content analysis (Creswell 2009). Two of the researchers independently coded the data, and a third researcher audited the findings. An inter-coder reliability of $93 \%$ was achieved.

\section{Procedures in teaching 3D printing}

\section{Step 1: Conceptual understanding of 3D printing and its usage}

The importance of 3DP in the 4th Industrial Revolution (Korea Design Promotion Agency 2016) was first explained to the students. This industrial revolution means that the whole process from manufacturing to service is digitalized, because of the inclusion of big data, artificial intelligence, cloud, robotic engineering, and 3DP in the product development process. With the definition of 3DP, the additive forming method was explained in order to let the students know how 3DP is made. During this stage, the 
students were introduced to the 3D modeling process that is needed for 3DP and brief introduction of each 3D modeling software (e.g., MAYA, Rhino, Sketchup, 3Ds MAX) was given with explanation about the characteristics and appropriate applications of each software. The rationale of selecting Rhino for the class training was also provided to the students.

In addition, a variety of 3DP applications in art, manufacturing industry, medicine, and fashion were introduced, with its benefits of saving time and money in the product design, development, and production process. To enhance the level of students' understanding of 3DP and its use as well as their motivation to generate 3D design ideas for the 3DP practice, many examples of 3DP applications in arts and fashion designs were shared with the students. The examples of the current industry's 3D printed products were also introduced to the students for their design inspiration.

\section{Step 2: Practice of 3D modeling using Rhino tools}

Rhino has an easy interface for users to use, but its various tools and functions may make novices feel difficult to get familiar with. Considering this matter, at the beginning of this course, the instructor focused on making the students get familiar with its interface by fully introducing the basic tools, which covers the 2D process of drawing lines and circular curves (Choi 2014). The students then started to practice the way to make a surface, a single side of triangle, square, or polygon, by using $2 \mathrm{D}$ process because this process is fundamental but essential when using Rhino for 3D modeling. Followed by the activity of this basic 2D process, they learned the 3D modeling process; for example, surfaces form a solid, consisting of plural surfaces such as triangular pyramid, cylinder, or cube. This 3D modeled solid form can be 3D-printed.

Rhino provides more than 30 different ways for users to draw various lines (e.g., line drawing, curve drawing, arc drawing). Due to its various methods of drawing, Rhino tools have more than 2000 functions, which make almost impossible to handle all of the tools during the class activities of one semester. Therefore, its most important and common functions during the 3D modeling process were introduced in the classes (e.g., drawing lines and extruding them, revolving lines to make a surface, cutting surfaces and transforming them, copying them in symmetrical directions as a mirror function, arranging them). This practice was performed for the 4 weeks of the total 16-week class period.

\section{Step 3: Practice of 3D object creation}

The students were asked to make real objects with the basic tools after learning how to use Rhino tools and functions. For instance, they tried making a finger ring, which is simple and easy to design and make, and then add their own additional design features to the ring by experimenting the functions they had learned until then. Thereafter, they were able to learn more of Rhino tools while making many kinds of objects such as buttons and clocks. At the beginning when introducing the way to use Rhino tools and functions, it was challenging for the fashion design students to get fully familiar with those tools and functions until they were given numerous opportunities of making various forms of simple 3D objects; of watching the instructor's demonstration of using 
tools; and of learning and practicing additional functions. This practice took around 4 weeks of class time in one semester.

For the next step, the students were introduced to learn 3D rendering by adding lights and textures to the 3D designed objects so that they could look like a real product. Due to limited time for the students to learn V-ray or Key-shot in one semester, fundamental rendering contained in Rhino was taught to the students, with opportunities of multiple $3 \mathrm{D}$ rendering practices. The students spent around $2 \mathrm{~h}$ for this exercise.

\section{Step 4: Process of 3D fashion object creation}

On the basis of skills to use Rhino tools and experience of making simple 3D objects, the students were challenged to come up with their own 3D designs based on their original design inspiration. Considering the students' learning curve because of this 3DP experimental course as the first time to introduce the 3DP concept in the fashion design major, we tended to focus on creating simple and small-sized fashion-related items. They were then required to capture the images for the process of modeling their 3D objects and to record each design stage in details. For the creative 3D modeling, they were allowed to design small fashion items, considering the size and capability of 3D printers available in the fashion department.

Table 2 presents the production process of a student's self-designed 3D modeling, which includes five steps: (1) conceptualization to create a Korean traditional-style hairpin, (2) collage and review of inspirational images (e.g., variety of traditional-style hairpin images), (3) idea sketches of hairpin by hand, (4) 3D modeling of the hairpin using Rhino, and (5) 3D rendering of hairpin. All 17 students in this experimental course followed this procedure to create their $3 \mathrm{D}$ objects.

\section{Step 5: 3DP prototyping}

After the completion of 3D modeling using Rhino, it was exported to a STL file, which downloaded in CURA, the slicing software. After confirming the appearance of supporting structures by turning the object around, each student needed to convert it into G-code and save it in a SD card. Then, a 3D printer downloaded the saved file from the SD card and started 3DP of the object. Considering this 3DP experimental course as the first time to include the concept in the fashion design major at the institution, we aimed to build this course for creating simple and small-sized fashion accessories, which took the minimum of $30 \mathrm{~min}$ to maximum of two hours depending on the simplicity of outputs. Sandpapering of a 3D printed object made its surface even. The completed 3D printed designs by the seven students among the 17 students' creative 3D objects are shown as examples in Table 3. Finger rings were the most popular 3D objects to create and print by six students, followed by pendants, other accessories and hairpins. Table 3 presents the following selected examples of students' 3D printed objects in the 3DP course: three finger rings, one pendant, one hairpin, one accessory, and one earring.

As shown in Table 3, the student 1 made a finger ring by twisting curves. The student 1 made a circle, and used the functions of polyline, split, and sweep rail to make a twisted ring of which two curves are harmonized. The student 2 designed a mechanical finger ring with inspiration from details of tough but elaborative and structural machines including layered metal plates and nails. The functions of circle, extrude, split, sweep 
Table 2 3D modeling process of a student's self-designed object

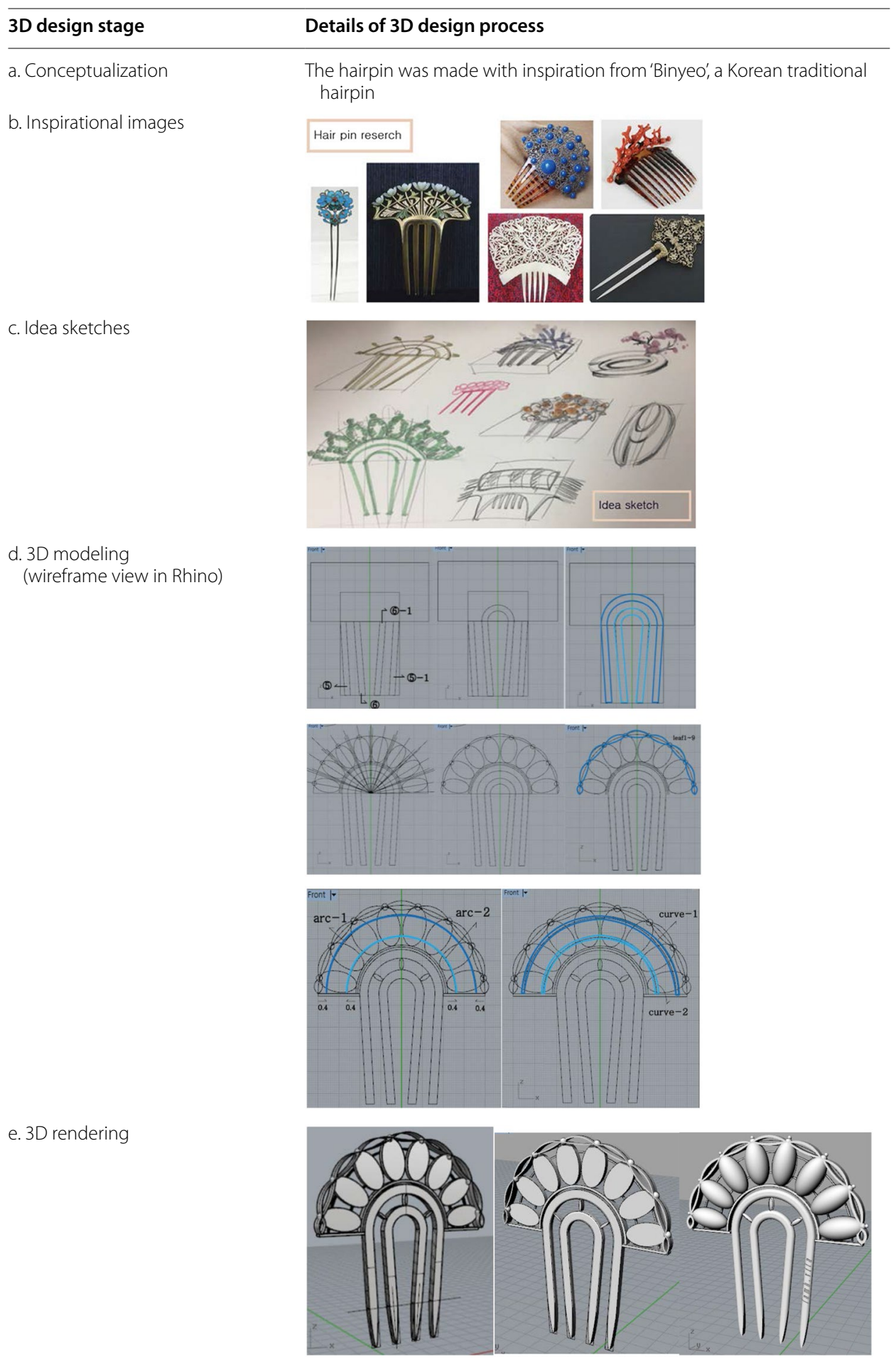

rail, revolve, Boolean difference and fillet were harmoniously applied, which led to stylish, modern and unique design. 
Table 3 Selected 3D printed objects from the 3DP course

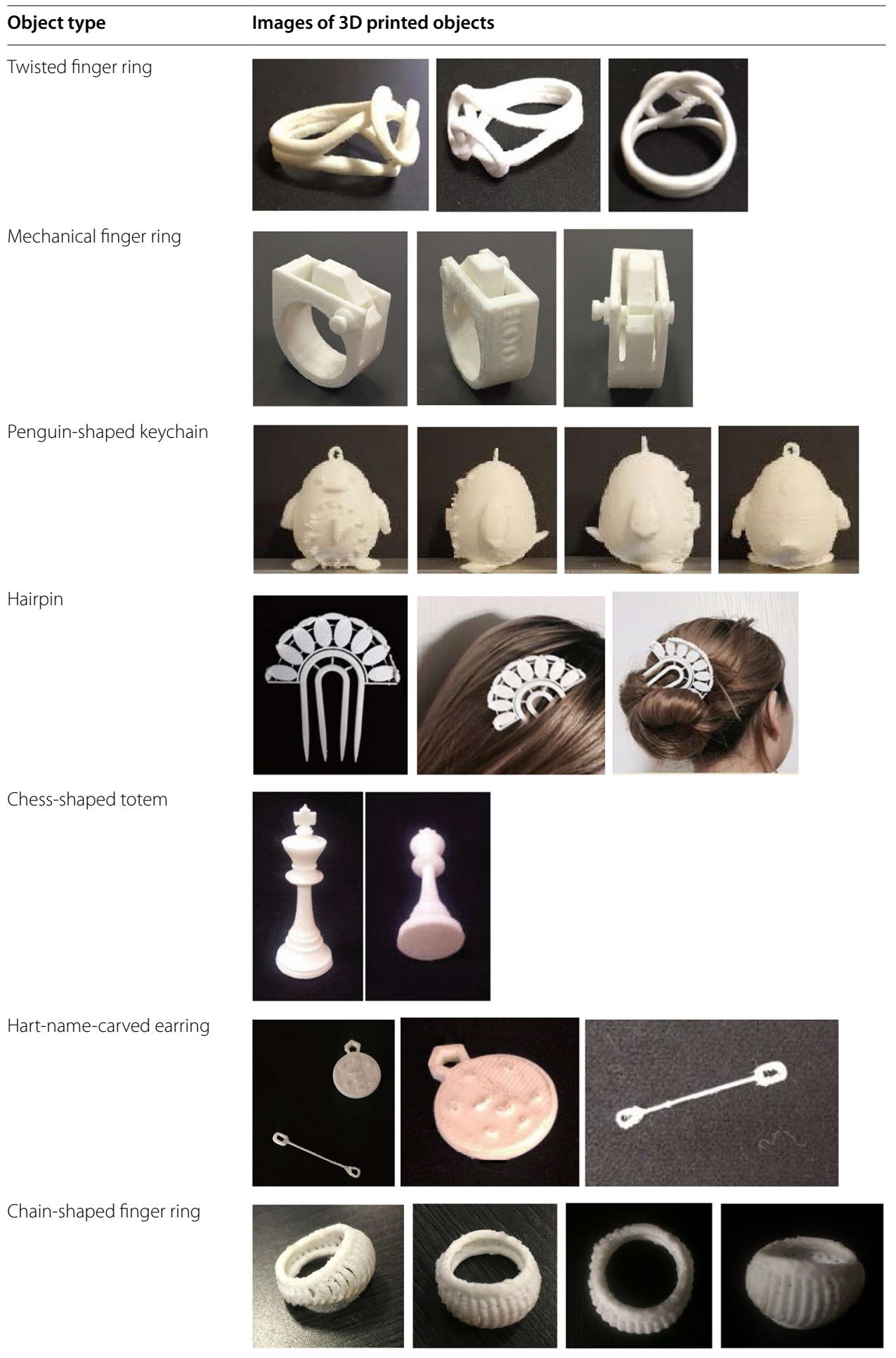

The student 3 designed a keychain of penguin shape, which is characterized by a clock attached to the penguin's body. The shape of a small animal is not only suitable for 3DP, but also can be used as a keychain or another accessory. By the use of the functions of 
sphere, mirror, ellipse solid, rotate, sweep rail and polar array, the penguin's body, arms, legs and the attached clock were created. The student 4 made a hairpin with inspiration from Binyeo, a Korean traditional hairpin. By repeatedly using the functions of polyline, mirror, arc, explode, ellipse, extrude, Boolean difference, and fillet, its straight lines and leaf shape were developed.

In the fifth object shown in Table 3, the student 5 made own totem with inspiration from 'Bishop', one of the chess pieces and the heroine's totem in the movie 'Inception'. In the movie, totem acts as the only item that enables to distinguish whether the characters are in reality or in a dream. While hoping that this 3DP would play an important role for this student like the totem in the movie, the student 5 made 'King', the most important piece in chess as own totem. Modeling a chess piece was very simple. It could be simply modeled by drawing the silhouette using polyline and curve tools, and revolving the line to complete it. If the silhouette shape was complicated, an alternative method of opening an image of a chess piece and tracing its form could be chosen. Two other students were inspired by unique accessory designs and created hart-name-carved earring and chainshaped finger ring.

In addition, every one of the students than those mentioned in Table 3 freely modeled their designs and were able to produce their 3D printed objects including pendant, earring, key-shaped object inspired by a movie, decorated cup, and finger ring. Different shapes of finger rings the students created include those of leaf-shaped, lego-based, watch-shaped, chain-shaped, and name-carved. They also created initial-printed or watch-printed pendants, key-hole-shaped accessory inspired from a specific movie, and Holy Grail of Christianity.

\section{Summary of 3D printing education}

A semester-long 3DP education in the fashion design course, "Digital Fashion Design," provided a valuable learning experience for both the instructor and students, which leads to beneficial insights of 3DP education in the fashion discipline of higher education. The 17 students who took this 3DP course in fall 2016 became to understand 3DP and its application in fashion more thoroughly and to gain more interest of using 3DP in fashion-related product design and development process.

Toward the end of the semester, the students seemed to be more comfortable to use 3D modeling software and 3D printers, which proved they overcame their initial challenges (e.g., being scary of learning Rhino, confusion of understanding different Rhino tools). They originally expected 3DP to be very complicated and hard to learn, but after the semester-long 3DP education, they became to have confidence to use 3DP and expressed the high interest in making more efforts to integrate 3DP in their fashion-related prototype creation. During the 3DP practice, the last stage of this experimental course, the students' capacity of using 3D modeling software, Rhino, was much more improved than the beginning of fall semester, which allowed them to comfortably adjust their own 3D models without any hesitation.

In addition, those who had been interested in learning 3DP because of the current public and industry trends and demands had actual experiences of using 3DP in the design and prototype development process. A majority of them expressed their willingness to learn more advance skills of addictive manufacturing, 3DP, through an advanced 
course if offering. Thus, their desires to produce fashion-related items by using 3DP have dramatically grown after having actual in-class learning experiences of designing and producing 3D personalized objects that they have engaged into the entire design process.

These students also became to be more proficient for using 3D modeling software, here Rhino, to develop different kinds of 3D objects. By encountering Rhino that helps users to model their own designs in a 3D space, a majority of them expressed their desires to further practice this 3D modeling software in spite of its complexity of learning, as well as to challenge themselves for modeling of more delicate and wearable fashion products.

Furthermore, many of them showed their aspirations to participate in 3DP contests (e.g., jewelry design contest) in the future. The 17 students expressed that 3DP was not that difficult to learn and implement in their design process after completing the semester-long course, and some of them expressed their interest to incorporate this 3DP into their future design career by establishing a startup company, which will allow to produce personalized fashion products with a small quantity. In terms of the different types (e.g., ring vs. penguin) and (or) shapes of objects the students chose to create, no different challenges were identified among the students when creating their 3D objects and printing.

Followed by the College grade policy, excluding the students who receive $\mathrm{D}$ and $\mathrm{F}$ in class, 25,45 , and $30 \%$ of the students should receive A, B, and C, respectively. All of 17 students successfully completed this 3DP course; 4 students received the letter grade of A followed by 7 for B and 6 for C. This grade was calculated based on the students' class attendance (10\%), assignments (30\%; weekly journals, in-class activities), and final project (60\%; 3D modeling files, 3D printed output, written report of 3D design process). Students' 3D models were evaluated on geometrical accuracy, application of appropriate tools, utilization of various tools, and error checking.

Several challenges were associated with teaching course contents in this 3DP course. Although the students had sufficient exposure to use different types of 2D and 3D software before taking this 3DP course, it was such a big challenge for the instructor to make all 17 students understand the way to operate Rhino, from the beginning to the middle in the course. Especially for the 3D modeling process, students had difficulties to understand $x-y-z$ direction in a virtual 3D space, to relate this $x-y-z$ setting with their $3 \mathrm{D}$ object design, and to visualize their input measurements as 3D objects. In the 3DP practice stage, only two 3D printers the department equipped was available for students to print their 3D objects, which was another challenge of this course because of limiting the efficient use of students' time. In some cases, students were not able to print their works in a timely manner due to technical errors of 3D printers. In such situations, it took time to settle the problems within the limited time, which was another challenge.

In general, there was an educational effect through 3DP lessons that the students were able to more deeply understand the current market demands and use of 3DP in various industries including fashion and gain their interest in 3D modeling and 3DP in the fashion field. On the other hand, there were too many topics related to 3DP and 3D modeling to cover during one semester, so it is recommended to consider dividing the 3DP learning course into various levels; for example, basic and advanced courses during two semesters, in order to reflect the students' feedback on their interest to take an advanced 3DP course for one more semester if available. 


\section{Discussion and implication}

This experimental case study was conducted to examine what and how higher education, specifically fashion-related disciplines, should approach and teach fashion students about 3DP and its practical implementation into the fashion product design, which has been gaining much attention in the public and various digital manufacturing fields for the past 10 years. By sharing our 3DP teaching experience with the students in the fashion design major, we aimed to provide a pedagogical guidance for educators in similar design disciplines at other institutions.

Through this 3DP course, the students were able to learn the entire process of 3DP from modeling to printing, and it was evaluated that they have become to achieve for (1) making 3D modeling of their own design by acquiring the skills of operating 3D modeling software and (2) understanding the operating principles of 3DP and its production process. This case study provides an initial foundation of 3DP education in fashionrelated majors of higher education by introducing the emerging technology, 3DP, to students in these majors, who will eventually graduate and work in the fashion industry where design innovation and technology are ceaselessly incorporated and attempted.

Engineering-based 3D modeling software have been taught at many private institutes; however, their curricula are mostly organized for general product design and (or) 3D modeling software learning instead of being specialized into 3D wearable fashion product design (e.g., dress, jacket). In addition, 3DP tutorials have been provided by most of 3D printer manufacturers, but this simple tutorial (e.g., making a simple 3D object) is insufficient for fashion students to design sophisticated wearable products using 3DP. Therefore, the course used for this case study was indeed a great trial (1) to introduce 3DP to fashion design students by integrating this topic into the fashion design curriculum and (2) to experiment 3DP education in fashion for one semester in order to seek out suggestions, which can guide for future implementation of 3DP.

This 3DP course allowed the researchers to identify the key obstacles fashion students could face when learning the entire 3DP process from modeling to printing for fashion-related item design and to provide some guidance for different levels of 3DP related courses needed to be offered in future. One semester, the 16-week period, was too tight for the students to learn the 3DP concept and 3D modeling software as well as trying design planning, 3D modeling, and 3D printing for one 3D object. It would be desirable to reduce the time spent to learn the basic Rhino tools at the beginning of course, in order to give more times for students to create their own 3D objects and 3DP practices.

$3 \mathrm{D}$ modeling is one of the most important processes in 3DP because it is the foundation for the precise printing of 3D designs; however, the biggest challenge was related with teaching how to use Rhino in this 3DP course. Although the students had fluent knowledge of using 2D and 3D fashion-related design software, Rhino was very new to them for learning. Mostly students who enter into fashion-related program were not expected to take the heavy emphasis on courses such as physics, mathematic, and sciences in their high school period. Lack of these fundamentals in science, technology, education, and mathematic (STEM) might make the students to be challenged for absorbing the logic of Rhino at the beginning of this course. One way to minimize this challenge may be for fashion students to take the introduction of 3D modeling program, 
Rhino, from other programs (e.g., industrial engineering) before taking 3DP courses for wearable fashion products that are offering in the department.

Fashion students should have sufficient practices to use one of 3D modeling software, Rhino, before engaging into creating complicated wearable fashion products for 3DP, which means it is impossible to shorten the learning period of Rhino tools. Considering redesigning a fashion design curriculum incorporating 3DP, it may be also suggested for offering an introductory course of 3D modeling software, Rhino before taking a semester-long 3DP course for wearable fashion product design. This approach will allow students to equip necessary 3D modeling skills for an advanced 3DP course.

One semester was not sufficient for the students to learn and develop wearable fashion products using 3D modeling software and 3D printer. This 16-week period was enough to learn the modeling software, create simple 3D objects, and print those. There was not enough time to introduce key design elements (e.g., mobility, functionality, durability) that students need to consider when creating wearable fashion products. It is crucial to teach different types of fabric structures so students can consider those when developing 3DP clothes since the flexibility of a material is the key feature for wearers' comfort and mobility; this is the current challenge of 3DP in fashion. It is good to offer another 3DP course focusing on designing and developing flexible fabric structures using Rhino tools as well as creating $3 \mathrm{D}$ printed wearable products.

For enhancing students' level of understanding for wearable 3DP, it would be good to incorporate the analysis of current designers' 3DP examples into 3DP course contents (e.g., analyzing the structural characteristics of 3DP design works by Iris Van Herpen). This tells that wearable fashion products with 3DP are beyond having the skills of 3D modeling and 3DP. Students should have in-depth knowledge of science, technology, education, and mathematic (STEM), along with creative and innovative thinking skills. Accordingly, it would be effective to make the curriculum of two semesters by dividing into the fundamental and advanced 3DP courses or to provide a few times of extra-curricular classes, in order for students to have an opportunity to develop a wearable fashion products considering functional, expressive, and aesthetic needs. It would also be desirable to make it as a team project since wearable fashion items are bigger in scale than accessories.

During the 16-week period of 3DP education in the fashion design major, one major limitation of 3DP for wearable fashion products was identified, which is connected with its technical aspect, specifically materials used for 3DP. The 3DP material is mainly plastic, which is inappropriate for wearable fashion products in terms of flexibility. Flexible filaments made from the material of rubber properties are available, but still lack of flexibility to be used as a wearable material although it can be acceptable for sandals or other accessories. In addition, in the case of flexible filaments, it is difficult to remove the supporter of 3D printed objects and there is a high possibility of failure when an object is printed at high speed. Therefore, it is urged to develop and universalize more flexible and eco-friendly materials that can be used for 3D wearable product design. To overcome the lack of flexibility of such materials, it is also suggested to print objects as thin and small as possible, which can supplement the hard feeling of plastics. This can be considered as a modular design approach; small pieces of 3D modular objects are printed and those pieces connected together, which leads to enhance the mobility of a wearable product. 
In the 3DP course for this case study, types of materials available for 3DP were not thoroughly introduced and explained to the students because of the time constraints. The students only had tactile experiences of their simple and small 3D printed objects by touching. To advance this course more focusing on wearable fashion products (e.g., vest, jacket, dress), it is necessary for instructors to teach students the woven and knit structures of fabrics and the way to incorporate these structures when creating wearable products by applying articulated hinges or links using computational design. In addition, it is suggested for instructors to introduce students the use of other technologies (e.g., $3 \mathrm{D}$ body scanner, portable object scanner) in the 3DP process for developing 3D printed wearable fashion products.

This case study provided a pedagogical guidance to educators in the fashion discipline by presenting one case of 3DP education in one of fashion design courses. This study presented the importance of 3DP in fashion design curricula and the way to strategically integrate this technology into the curriculum. The findings of this study also presented several limitations of 3DP for wearable fashion product design as of today and provided suggestions for fashion professionals.

Authors' contributions

YMK, YAL, and SJK originated the research idea. YMK carried out research and draft the first manuscript. YAL guided study design, data analysis and interpretation, and manuscript draft and its revision. SJK contributed to the 3DP course design that was used for this study. All authors read and approved the final version..

\section{Author details}

${ }^{1}$ Department of Fashion Design, Sejong University, 209 Neungdong-ro, Gwangjin-gu, Seoul 05006, South Korea.

2 Department of Apparel, Events, and Hospitality Management, lowa State University, 2302 Osborn Drive, Ames, IA 50011-1078, USA.

\section{Acknowledgements}

This research was supported by the MISP (Ministry of Science, ICT \& Future Planning), South Korea, under National Program for Excellence in Software Program (the SW oriented college support grogram) (R7718-16-1005) supervised by the IITP (Institute for Information \& communications Technology Promotion).

\section{Competing interests}

The authors declare that they have no competing interests.

\section{Publisher's Note}

Springer Nature remains neutral with regard to jurisdictional claims in published maps and institutional affiliations.

Received: 7 May 2017 Accepted: 1 September 2017

Published online: 28 December 2017

\section{References}

3D printer and 3D printing news. (2013). MGX introducing new 3D printed hats. Retrieved from http://www.3ders.org/ articles/20130222-mgx-introducing-new-3d-printed-hats.html.

3D printer and 3D printing news. (2015). SOLS unveils ADAPTIV, robotic, 3D-printed shoes that dynamically adjust pressure and shape to fit you. Retrieved from http://www.3ders.org/articles/20150215-sols-unveils-adaptiv-robotic3d-printed-shoes-adjusts-pressure-and-shape.html.

Adidas Group. (2015). Adidas breaks the mould with 3D-printed performance footwear. Retrieved from http://www.adidasgroup.com/en/media/news-archive/press-releases/2015/adidas-breaks-mould-3d-printed-performance-footwear/.

America Makes. (2013). America Makes is the national additive manufacturing innovation institute. Retrieved from https:// www.americamakes.us/news-events/press-releases/item/4-america-makes.

Baek, S. H. (2015). Introduction of 3D printing technology \& applications. Korean Industrial Chemistry News, 18(1), 2-10.

Burgess, M. (2016). Adidas is selling a limited number of 3D-printed runner shoes. We tried them out. WIRED. Retrieved from http://www.wired.co.uk/article/adidas-3d-printed-running-shoe-cost-test.

Choi, S. G. (2014), Rhino 3D 5.0 advanced. Paju: Heyjiwon.

Columbus, L. (2015). 2015 Roundup of 3D printing market forecasts and estimates. Forbes. Retrieved from https:// www.forbes.com/sites/louiscolumbus/2015/03/31/2015-roundup-of-3d-printing-market-forecasts-andestimates/\#551dfe481b30. 
Creswell, J. W. (2009). Research design qualitative, quantitative, and mixed methods approaches (3rd ed.). Thousand Oaks, CA: Sage Publications Inc.

Designboom. (2013). 3D printed bow tie by monocircus. Retrieved from https://www.designboom.com/ design/3d-printed-bow-tie-by-monocircus/.

Engadget. (2016). Nike used 3D printing and Olympic sprinters to design its new track shoe. Retrieved from https://www. engadget.com/2016/08/03/nike-zoom-superfly-elite-3d-printing-olympics/.

Garfield, L. (2016). Under Armour 3D-printed soles for its new $\$ 300$ sneakers with powder and lasers. Retrieved from http:// www.businessinsider.com/under-armour-3d-prints-its-new-architech-shoes-2016-6/\#this-is-the-architech-thesneakers-are-fit-for-any-type-of-sport-the-lighthouses-director-adam-bayer-tells-tech-insider-1.

Gross, D. (2013). Obama's speech highlights rise of 3-D printing. Retrieved from http://www.cnn.com/2013/02/13/tech/ innovation/obama-3d-printing/.

Hara, Y. J. (2015). Hyun, J. W. (Translated by). Introduction and production of 3D printer. Seoul: Info the books.

IBISWorld. (2017). 3D printer manufacturing: market research report. Retrieved from https://www.ibisworld.com/industrytrends/specialized-market-research-reports/technology/computer-semiconductors-systems/3d-printer-manufacturing.html.

Kim, H. S., \& Kang, I. A. (2015). Study on status of utilizing 3D printing in fashion field. Journal of the Korea Fashion \& Costume Design Association, 17(2), 125-143.

Kim, Y. S., \& Lee, J. A. (2015). Formative characteristics of 3D printing fashion from the perspective of mechanic aesthetic. The Research Journal of the Costume Culture, 23(2), 294-309.

Korea Design Promotion Agency. (2016). Start line of 'Fourth Industrial Revolution': Design trend 2017. Paju: Sam and Parkers.

Kuhn, R., \& Minuzzi, R. F. B. (2015). The 3D printing's panorama in fashion design. Moda Documenta: Museu, Memoria e Design, 11(1), 1-12.

Lee, K. A. (2015). Prospects for 3D modeling-based 3D printer in art education. Art Education Research Review, 29(3), 149-174.

Lee, I. H., Shin, J. M., \& Cho, H. Y. (2015). Design and operation of 3D printing education curriculum in mechanical engineering. Journal of the Korean Society of Manufacturing Process Engineers, 14(3), 21-26.

Lim, D. W. (2014). To 3d printing share 15\% of the world. The science times. Retrieved from http://www.sciencetimes. co.kr/? $=123517 \&$ post_type $=$ news\&paged $=9$.

Logan, L. (2015). The Dutch designer who is pioneering the use of 3D printing in fashion. Retrieved from http://www.smithsonianmag.com/innovation/dutch-designer-who-pioneering-use-3d-printing-fashion-180957184/.

Luimstra, J. (2014). Iris van Herpen 3D printed an ice-like dress. Retrieved from https://3dprinting.com/fashion/ iris-van-herpen-3d-printed-ice-like-dress/.

Luimstra, J. (2015). Artist got inspired by waves and created this 3D printed swimsuit. Retrieved from https://3dprinting.com/ news/artist-got-inspired-waves-created-3d-printed-swimsuit/.

Matich, D. (2015). Karl Lagerfeld showcases 3D printed Chanel at Paris fashion week. 3D printing industry. Retrieved from https://3dprintingindustry.com/news/ karl-lagerfeld-showcases-3d-printed-chanel-fashion-at-paris-fashion-week-53000/.

Mau, D. (2013). How 3-D printing could change the fashion industry for better and for worse. Retrieved from http://fashionista.com/2013/07/how-3-d-printing-could-change-the-fashion-industry-for-better-and-for-worse.

McKenna, B. (2016). 3D-printed shoe race: How do Nike, Under Armour, and Adidas stack up? Retrieved from https://www. fool.com/investing/general/2016/04/02/3d-printed-shoes-nike-underarmor-adidas-newbalance.aspx.

Melnikova, R., Ehrmann, A., \& Finsterbusch, K. (2014). 3D printing of textile-based structures by fused deposition modeling (FDM) with different polymer materials. In IOP Conference Series Material Science and Engineering (Vol. 62, pp. 012018). doi: 10.1088/1757-899X/62/1/012018.

Nam, S. W. (2012). Rhinoceros 3D bible for jewelry designers. Seoul: Taehakwon.

Nike News. (2014). Nike football accelerates innovation with 3D printed "concept cleat" for shuttle. Retrieved from http:// news.nike.com/news/nike-football-accelerates-innovation-with-3d-printed-concept-cleat-for-shuttle.

Nike News. (2016). Nike zoom superfly flyknit. Retrieved from http://news.nike.com/news/allyson-felix-track-spike.

Noh, S. H., \& Lee, W. M. (2016). 3D printer for beginners. Seoul: Daegwangseorim.

Park, S., \& Yoo, Y. (2016). A case study on collaborations in 3D printing fashion. Journal of the Korean Society of Costume, 66(7), 124-138.

Pensar Development. (2017). Pensar DNA shoe. Retrieved from http://pensardevelopment.com/projects/ dna-shoe-concept/.

Perry, A. (2017). 3D-printed apparel and 3D-printer: exploring advantages, concerns, and purchases. International Journal of Fashion Design, Technology and Education, 1-9, doi:10.1080/17543266.2017.1306118.

Reebok News Stream. (2016). Reebok introduces new liquid factory. Retrieved from http://news.reebok.com/global/ latest-news/reebok-introduces-new-liquid-factory/s/8a87d7f7-8a93-49d2-9ddd-efee2d588b76.

Shapeways. (2013). Why president Obama mentioned 3D printing in the State of the union address. Retrieved from https:// www.shapeways.com/blog/archives/1921-why-president-obama-mentioned-3d-printing-in-the-state-of-theunion-address.html.

Shin, Y. M. (2015). Types and applications of 3D printers. Polymer Science and Technology, 26(5), 404-409.

Song, A. R., \& Geum, K. S. (2016). A study on the formative characteristics of fashion design using 3D printing technology: focused on iris van herpen. Journal of Basic Design \& Art, 17(2), 220-230.

Song, B. B., \& Seok, J. H. (2015). Education of 3D printing in university, Korea University Newspaper. Retrieved from http:// news.unn.net/news/articleView.html?idxno=147764.

Under Armour 3d-architech. (2016). Retrieved from https://www.underarmour.com/en-us/3d-architech.

Van Herpen, I. (n.d.). Voltage couture. Retrieved from http://www.irisvanherpen.com/.

Vanderploeg, A., Lee, S.-E., \& Mamp, M. (2017). The application of 3D printing technology in the fashion industry. International Journal of Fashion Design, Technology and Education, 10(2), 170-179.

Yap, Y. L., \& Yeong, W. Y. (2014). Addictive manufacturing of fashion and jewellery products: a mini review. Virtual and Physical Prototyping, 9(3), 195-201. 